\title{
GAMMA KNIFE RADIOSURGERY ROLE IN THE MANAGEMENT OF BRAIN STEM CAVERNOUS ANGIOMAS
}

\author{
Ahmed Ragab AbdelSalam ${ }^{1}$, Ayman Abd Elraouf Abd Elghafar Elshazly ${ }^{2}$, \\ Ahmed Faisal Tobar ${ }^{2}$, Ahmad Mohamed Abd Raheim Elsabaa ${ }^{2}$ and \\ Sameh Roshdy Tawadros ${ }^{2}$
}

\author{
${ }^{1}$ Military Medical Academy \\ ${ }^{2}$ Department of Neurosurgery, \\ Faculty of Medicine, Ain Shams \\ University, Cairo, Egypt \\ Corresponding Author: \\ Ahmed Ragab AbdelSalam \\ Mobile: 201065420803. \\ E-mail: \\ docragab@gmail.com
}

Received : 27/5/2020

Accepted: 22/6/2020

Online ISSN: 2735-3540

\begin{abstract}
:
Background: Cavernous angioma or cavernoma is a benign vascular malformation, which can be found at any region within the brain. Brain stem cavernous angioma is rare. Although the optimal management of intracranial cavernous angiomas is open resection, Gamma Knife radiosurgery (GKR) has played an important role in treating these deeply seated and high surgical risk malformations throughout the past 20 years.
\end{abstract}

Aim of the study: Our study aimed to evaluate the efficacy, and safety of Gamma Knife radiosurgery in the management of brainstem cavernous angiomas.

Patients and Methods: Our retrospective study was conducted on 22 patients with brainstem cavernous hemangioma who underwent gamma knife at the Gamma Knife center (GKC), Nasser Institute Hospitals, Cairo in collaboration with department of neurosurgery, Ain Shams University. Follow up period 24-132 months, mean follow up period 51 months.

Results: In the present series we have satisfactory results as regards reducing rebleeding rate, we have post radiosurgery rebleeding rate of 2.8\%. It represents the sum of the bleeding rate for all patients in the study including those who have rebleeding rate $30 \%$ preradiosurgical. As regards control of improvement of presenting manifestations, we have also excellent results in the present series (75\%) of patients showed improvement of the symptoms, (25\%) remained stable clinically. Reduction of cavernoma size after treatment was observed also in our series for $77.3 \%$ of the lesions. There was no permanent morbidity post gamma knife, only 3 transient morbidities were happened due to edema and bleeding.

Conclusion: As the development of stereotaxic radiosurgery and more experience accumulated, GKR has become an effective and safe alternative method for brainstem cavernous angiomas treatment.

Keywords: Radiosurgery, gamma knife, brainstem cavernoma, brainstem angioma, brainstem hemangioma.

\section{Disclosure:}

The authors report no conflict of interest concerning the materials or methods used in this study or the findings specified in this paper. The authors confirm that this paper has not been published in its current form or substantially similar form elsewhere including on a website and also it has not been accepted for publication elsewhere.

\section{Funding}

No funding was received for this research. 


\section{Ahmed Ragab AbdelSalam, et al.,}

\section{Conflict of Interest}

All authors certify that they have no affiliations with or involvement in any organization or entity with any financial interest (such as honoraria; educational grants; participation in speakers' bureaus; membership, employment, consultancies, stock ownership, or other equity interest; and expert testimony or patent-licensing arrangements), or non-financial interest (such as personal or professional relationships, affiliations, knowledge or beliefs) in the subject matter or materials discussed in this manuscript.

\section{INTRODUCTION:}

The current treatment of choice for most symptomatic cavernous angioma is microsurgical resection; however, morbidity and mortality associated with the operation are especially high in surgically inaccessible lesions such as brain stem. Therefore, radiosurgery has been used as an alternative method of treatment and the primary goal of the radiosurgery is the prevention of repeated haemorrhage. Though the natural history of brainstem cavernoma and the use of radiosurgery in the management are still controversial issues recent studies reported reduction of recurrent haemorrhage after radiosurgery. Medical management is limited to seizure control and symptomatic relief of headaches ${ }^{1}$. For brainstem cavernous angioma, the goal of any treatment method is to control rebleeding and avoid complications from recurrence ${ }^{2}$.

\section{AIM OF THE STUDY:}

Our study aimed to evaluate the efficacy, and safety of Gamma Knife radiosurgery (GKR) in the management of brainstem cavernous angiomas.

\section{PATIENTS AND METHODS:}

Our retrospective study was conducted at the Gamma Knife center (GKC), Nasser Institute Hospitals, Cairo in collaboration with department of neurosurgery, Ain Shams University.
Between October 2001 and October 2018, Out of 48 patients with brainstem cavernous hemangioma who underwent gamma knife treatment, 22 patients were fulfilling the inclusion criteria of our study.

Study Inclusion Criteria were:

- Patients with radiological diagnosis of brain stem cavernous angioma.

- Patients who refused surgery.

Our exclusion Criteria were:

- Patients with disturbed conscious level either related to angioma or due to another causes.

- Patients who previously managed with endovascular intervention.

- Patients who previously managed surgically.

- Patients less than 2 years old.

- In the case of bleeding, radiosurgery in our patients was postponed for at least 3 months, but usually treatment was initiated 6 months after the bleeding episode.

The Leksell Gamma Knife (Elekta C), Perfection and Icon were used at Cairo gamma knife center in Nasser institute. Follow up period 24-132 months, mean follow up period 51 months in our study.

\section{RESULTS:}

\section{Patient's characteristics:}

The series included 22 patients 14 female and 8 male patients. 
The mean age was 31.4 years old (range 3-59 years).

Symptoms leading to the diagnosis were accidental in 2 patients, Cranial Nerve affection 11, Motor power deficit 11, sensory deficit 7, ataxia 5 and ten patients In this study has combined presentation of cranial nerve affection and neurological deficit.

Out of 22 patients, 11 patients presented with cranial nerve affection. 5 of them presented with isolated abducent nerve affection, 1 isolated trigeminal neuralgia, 2 isolated facial palsies, while only 3 cases presented with combined cranial nerve affection.

In this study 22 patients had 27 lesions, 7 lesions $(31.8 \%)$ were located in midbrain, 10 were in pons $(45.5 \%), 2$ lesions $(9.1 \%)$ were located in medulla and other 2 lesions $(9.1 \%)$ were located in the ponto-medullary junction. There was one lesion its brainstem exact site was not reported.
We had 19 patients $(86.4 \%)$ out of 22 patients had single lesion, 3 patients $(13.6 \%)$ had multiple lesions.

CM hemorrhage in this study is meaned by acute or subacute onset of symptoms accompanied by radiological evidence of recent extra- or intra-lesional hemorrhage. In this study we had 22 patients, 13 lesions (59.1\%) bled once and $5(22.7 \%)$ bled more than once, only $4(18.2 \%)$ showed no bleeding.

2 lesions out of 22 lesions ( $9 \%$ ) showed bleeding post treatment; both lesions showed bleeding 3 years after treatment.

In both cases, hemorrhage was presented by transient neurological deficit. Both cases were presented by bleeding before treatment.

The preradiosurgical annual hemorrhage rate was calculated as the number of preradiosurgical hemorrhages divided by all patient-years at risk, we assumed that patients were at risk for hemorrhage from their dates of birth.

Preradiosurgical annual hemorrhage rate

$=($ no. of pre radiosurgical hemorrhages $) \div$ (sum of all patient-years at risk from birth) $=23 \div 646 \times 100=\mathbf{3 . 5 6} \%$ per patient per year

To calculate the preradiosurgical annual rebleeding rate, the number of preradio-surgical recurrent hemorrhages was divided by the total number of risk years (for patients presented by hemorrhage) from the dates of initial hemorrhage to the dates of GKR.

\section{The pre-radiosurgical annual rebleeding rate}

$=$ (no. of preradiosurgical recurrent hemorrhages) / (sum of total no. of risk years from the dates of initial hemorrhage to the dates of GKR)

$$
=5 / 22 \times 100=22.72 \%
$$

\section{Postradiosurgical Annual bleeding rate}

$=$ Postradiosurgical hemorrhagic events / all patient risk years from the dates of GKR to the dates of 2 years follow up.

$0 / 44=0 \%$ within 2 year per lesion per year. 
The overall annual bleeding rate postradiosurgical for all patients throughout the follow up period

$=$ postradiosurgical hemorrhagic events / all patient risk years from the dates of GKR to the dates of last follow up

$$
=2 / 94=2.1 \%
$$

\section{Postradiosurgical Annual rebleeding rate for patients who were presented by hemorrhage}

$=$ recurrent post radiosurgical hemorrhagic events / patients (with hemorrhagic presentation) risk years from the dates of GKS to the dates of last follow up.

$$
=2 \div 71 \times 100=2.8 \%
$$

$>$ we have subgroup of 11 lesions presented by bleeding and were followed up more than 2 years

$>$ The annual rebleeding rate for this subgroup $=4 / 13.3=30 \%$

$>$ Post gamma knife rebleeding rate $=0 / 22=0 \%$ within 2 years.

$>$ More than 2 years $2 / 57=3.5 \%$

Statistical analysis revealed that a relationship between rebleeding post gamma knife and treatment volume; $\mathrm{p}$-value 0.005 .

\section{Improvement Of Pre Gk Clinical Manifestaion}

20 patients out of 22 patients were presented before GK treatment by manifestations mentioned before as cranial nerve affection, motor affection, sensory affection or ataxia. Only 2 patients were discovered incidentally.

Follow up of those patients after gamma knife revealed that 15 patients out of 20 patients (75\%) showed improvement of the symptoms, 5 cases $(25 \%)$ remained stable clinically.

More than half of patients who showed improvement get improved in first 6 months post GK treatment. Other 3 patients (20\%) show improvement by the period of 1 year. Another 3 patients $(20 \%)$ showed improvement in 24 months of follow up. One case shows improvement after 2 years of follow up.

\section{Volume of cavernoma after gamma knife}

Follow up of 22 patients post treatment with Gamma Knife revealed that

$>17$ lesions $(77.3 \%)$ became smaller than before treatment.

5 lesions of those were noticed to be disappeared during the follow up period, after 1 year in 2 patients, after 2 years in 2 patients, after 6 months in 1 patient.

5 lesions $(22.7 \%)$ had stable volume after 2 years follow up.

\section{Adverse Radiation Effects:}

$>3$ lesion (13.6\%) out of 22 patients developed adverse radiation effect (edema).

$>$ All three lesions developed transient edema,

$>$ No lesions developed permanent edema and cyst formation.

$>19$ lesions (86.4\%) out of 22 lesions did not develop edema.

The clinical presentation of edema post Gamma knife on the patients

$>$ Of those 3 lesions, which developed edema the clinical effects on patients were as follows;

$>$ Two patients developed no symptoms. 
Gamma Knife Radiosurgery Role In The Management Of Brain Stem Cavernous Angiomas

$>$ One patient had neurological deficit received corticosteroids.

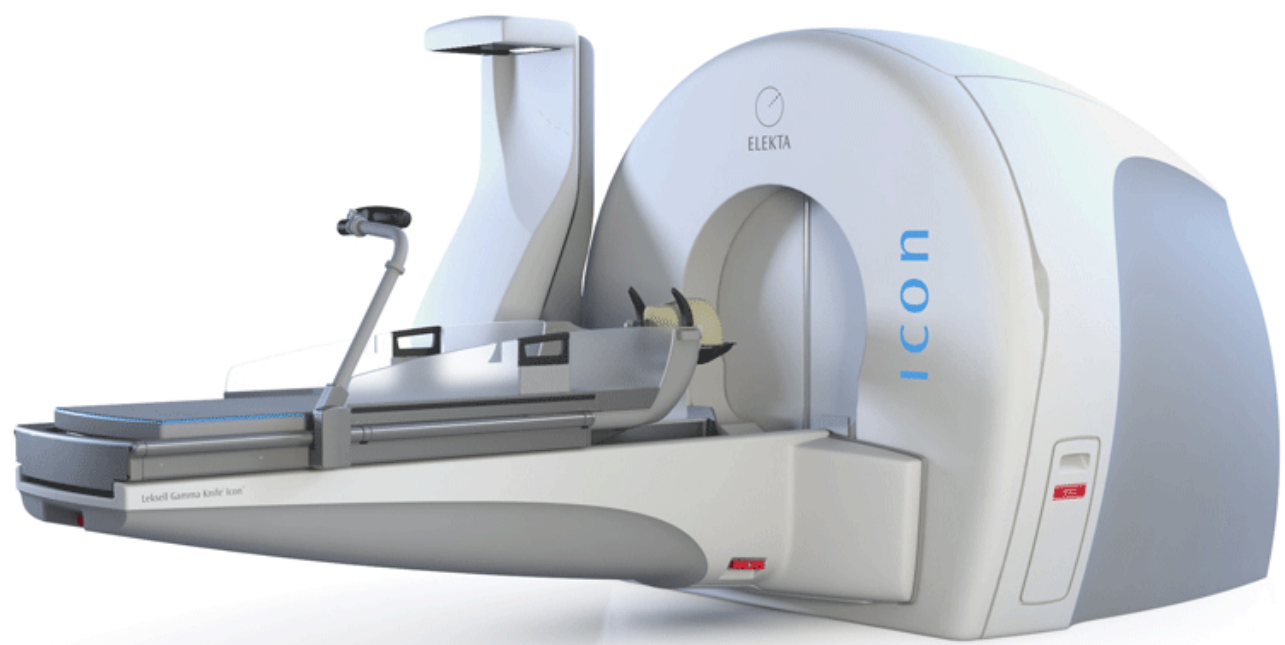

Figure (1): Leksell Gamma Knife ${ }^{\circledR}$ Icon $^{\mathrm{TM}}$.

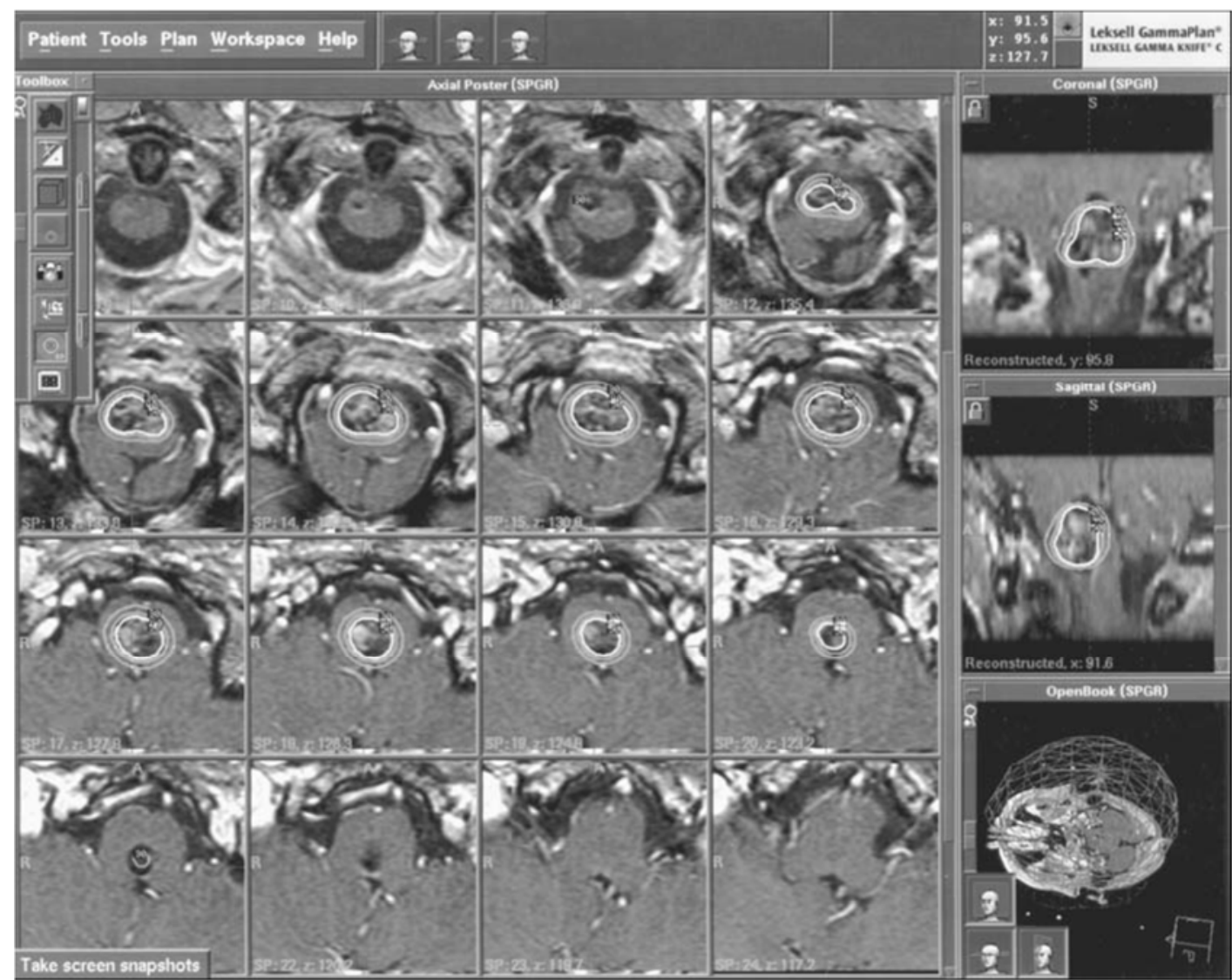

Figure (2): Gamma Knife radiosurgery dose plan for cavernous malformation of brain stem. Fifty percent isodose line (white line) projected on axial contrast-enhanced MR images with sagittal and coronal reconstruction covers the malformation. 


\section{Ahmed Ragab AbdelSalam, et al.,}

Table 1: Analysis of the annual risk of hemorrhage in radiosurgical series of patients with CMs.

\begin{tabular}{|c|c|c|c|c|c|c|c|c|}
\hline \multirow[b]{2}{*}{ Author } & \multirow[b]{2}{*}{ year } & \multirow[b]{2}{*}{ No of pt } & \multicolumn{3}{|c|}{ Method A } & \multicolumn{3}{|c|}{ Method B } \\
\hline & & & $\begin{array}{l}\text { No of } \\
\text { Hge }\end{array}$ & $\begin{array}{l}\text { Risk } \\
\text { years }\end{array}$ & $\begin{array}{c}\text { Annual } \\
\text { incidence }\end{array}$ & No of hge & $\begin{array}{l}\text { Risk } \\
\text { years }\end{array}$ & $\begin{array}{c}\text { Annual } \\
\text { incidenc } \\
\mathrm{e}\end{array}$ \\
\hline Amin-Hanjani et al., ${ }^{12}$ & 1998 & 95 & 132 & 2635 & $5 \%$ & 59 & 339 & $17 \%$ \\
\hline Pollock et al., ${ }^{7}$ & 2000 & 17 & 48 & 748 & $6.4 \%$ & 31 & 125 & $25 \%$ \\
\hline Tsien $^{13}$ & 2001 & 21 & 34 & 863 & $3.9 \%$ & 36 & 121 & $30 \%$ \\
\hline Hesegawa $^{14}$ & 2002 & 82 & 202 & 3091 & $6.5 \%$ & 120 & 354 & $34 \%$ \\
\hline Kim et al ${ }^{15}$ & 2002 & 22 & 30 & 750 & $4 \%$ & 10 & 28 & $36 \%$ \\
\hline Liu et al $^{6}$ & 2005 & 125 & 167 & NA & NA & 55 & 188 & $29 \%$ \\
\hline Present seris & 2020 & 22 & 23 & 646 & $3.6 \%$ & 5 & 22 & $22.7 \%$ \\
\hline & & & & ava & & & & \\
\hline
\end{tabular}

Table 2: shows the post radiosurgery hemorrhage rate and the morbidity found in other series

\begin{tabular}{|c|c|c|c|c|c|c|}
\hline & year & No of & Preradiosurg & Postradiosurge & Postradiosurgery & morbidity \\
\hline Kida et al., ${ }^{16}$ & 1999 & 100 & $32(5.299)$ & 7.3 & 5.2 & $8.9 \%$ \\
\hline Mitchell et al., ${ }^{17}$ & 2000 & 18 & $13+(6 \mp 9)$ & 4.5 & $3.7^{* *}$ & $16 \%$ \\
\hline Pollock et al. ${ }^{7}$ & 2000 & 17 & $24.8 \%$ & $8.8 \%$ & $2.9 \%$ & $41 \%$ \\
\hline Hasegawa et al., ${ }^{14}$ & 2002 & 82 & $34 \%$ & $12.3 \%$ & $0.8 \%$ & $13.7 \%$ \\
\hline Liu et al. ${ }^{6}$ & 2005 & 112 & $29.3 \%$ & $10.3 \%$ & $3.3 \%$ & $2.5 \%$ \\
\hline Kondziolka et al. ${ }^{18}$ & 2007 & 112 & $39.9 \%$ & $9.7 \%$ & $0.56 \%$ & $12.4 \%$ \\
\hline Nagy et al. ${ }^{19}$ & 2010 & 113 & $2.9 \%$ & $15 \%$ & $2.4 \%$ & $7.3 \%$ \\
\hline Monaco et al. ${ }^{20}$ & 2010 & 68 & $32 \%$ & $8.2 \%$ & $1.5 \%$ & $2.9 \%$ \\
\hline Lunsford et al. ${ }^{21}$ & 2010 & 103 & $32.5 \%$ & $10.9 \%$ & $1.06 \%$ & $13.5 \%$ \\
\hline Park \& Hwang ${ }^{23}$ & 2012 & 20 & $39 \%$ & $8.5 \%$ & $0 \%$ & $0 \%$ \\
\hline Lisck et al ${ }^{5}$ & 2013 & 112 & $2 \%$ & $3.2 \%$ & $0.5 \%$ & $0.9 \%$ \\
\hline Lee et al. $^{22}$ & 2013 & 49 & $31.3 \%$ & $(4.29 \%$ an & $3.6 \%$ & $4.1 \mid \%$ \\
\hline Sadeghi et al ${ }^{24}$ & 2014 & 100 & $\mathrm{NA}$ & $4.1 \mid \%$ & $1.9 \%$ & $12 \%$ \\
\hline Present seris & 2020 & 22 & $\begin{array}{c}3.6 \%(699) \\
22.7 \%\end{array}$ & $0 \%$ & $2.1 \%$ & $13.6 \%$ \\
\hline
\end{tabular}

Table 3: shows the effect of gamma knife on the volume of CM in different series.

\begin{tabular}{|c|c|c|}
\hline Author & year & $\%$ of volume reduction \\
\hline Present series & 2020 & $77.3 \%$ \\
\hline sadeghis et al ${ }^{24}$ & 2014 & $27.5 \%$ \\
\hline licak et $\mathrm{al}^{5}$ & 2013 & $53 \%$ \\
\hline Lunsford et al ${ }^{21}$ & 2010 & $57.5 \%$ \\
\hline p.Wang et al. ${ }^{23}$ & 2010 & $42 \%$ \\
\hline Kida y et al. ${ }^{16}$ & 2006 & $50 \%$ \\
\hline Hesegawa et al. ${ }^{14}$ & 2002 & $42.7 \%$ \\
\hline Zhang et al. ${ }^{25}$ & 2000 & $68 \%$ \\
\hline
\end{tabular}




\section{DISCUSSION:}

Controversies regarding radiosurgery of cavernomas arise from several aspects. First, knowledge of the natural course of the disease is not complete, and the definition of bleeding is ambiguous. Overt bleeding from a cavernoma (a blood clot inside or outside the hemosiderin ring of the lesion or evidence of hemorrhage after a lumbar puncture) is rarely diagnosed. Second, growth of the cavernoma observed in some cases could simply be bleeding with no symptoms in functionally silent areas. Third, no diagnostic tool so far can indicate cure in patients, At present, the positive effects of radiosurgery are identified by clinical observation and analysis of imaging changes on magnetic resonance imaging during a sufficiently long follow-up period which has a significant impact on treatment results. Unfortunately, treatment failure of cavernoma radiosurgery is diagnosed only after rebleeding occurs, which downgrades the results.

Interpreting the findings from natural history studies of CCMs is difficult because the available series have used varying inclusion criteria, study designs (retrospective or prospective), and definitions of bleeding.

Retrospective studies can be divided into 2 groups depending on the methodology used. With Method A, one simply divides the number of observed hemorrhages by the number of risk years. This method assumes that the patients are born with CMs and that the annual risk for hemorrhage is constant. In Method B, the number of observed hemorrhages is divided by the number of risk years as well, but both values are from the day after the first hemorrhage. Thus, the first hemorrhage as well as the time at risk before the first hemorrhage is excluded, making the method insensitive to the time of the development of the $\mathrm{CM}^{3}$.
We analyzed the annual risk of hemorrhage in radiosurgical series of patients with CMs, which selected only socalled high-risk patients. Using Method A, hemorrhage rates in these high-risk patients ranged between $2.3 \%$ and $6.5 \%$, but they became $17-36 \%$ when Method B was used. In the present series it is $2.2 \%$ with method A $19.6 \%$ with method B.

Salman et al $2012^{4}$, In a recently published population-based prospective cohort study, the 5-year risk of a first intracranial hemorrhage was $2.4 \%$ in patients who initially presented incidentally or with seizures. However, the same study showed that the 5-year risk of a second intracranial hemorrhage was $29.5 \%$ in those with a first intracranial hemorrhage at their initial presentation.

A tendency for decreased risk of rebleeding after the latent period of 2 years after radiosurgery has been found in the present series.

In the present seris it seems that bleeding rate increase postradiosurgical, but really it is much reduced for the ratio $2.7 \%$ represents the sum of the bleeding rate for all patients in the study including those who have rebleeding rate $23.89 \%$ preradiosurgical. Also not all patients in the present study were followed up for more than 2 years only 12 patients. Moreover, most of the patients treated at our center pay attention for follow up only when they have complains, on calling them they reported that they improved and they neglect to come back for follow up. Actually our results would be better than the documented results.

We have subgroup of 11 patients, they presented by bleeding preradiosurgical with rebleeding rate of $30 \%$. They were followed up for more than 2 year .they showed marked effect of gamma knife reduction of their rebleeding rate to be $0 \%$ in the first 2 years and $3.5 \%$ for more than 2 years. 


\section{Ahmed Ragab AbdelSalam, et al.,}

Statistical analysis in our study revealed that; a relationship between rebleeding post gamma knife and treatment volume; $p$-value 0.005 , cut off point $>4.6 \mathrm{cc}$.

Another important effect of cavernoma radiosurgery on improvement of pre $\mathrm{gk}$ clinical manifestaion

20 patients out of 22 patients were resented before GK treatment by manifestations mentioned before as cranial nerve affection, motor affection, sensory affection or ataxia. Only 2 patients were discovered incidentally.

Follow up of those patients after gamma knife revealed that 15 patients out of 20 patients $(75 \%)$ showed improvement of the symptoms, 5 cases $(25 \%)$ remained stable clinically.

One of the detectable effects after radiosurgery is regression of the cavernoma, which was observed in 17 lesions $(77.3 \%$ of lesions in the present series), usually within 2 years after treatment, 5 of them disappeared. Remaining 5 patients revealed no changes is size. Spontaneous regression of the cavernoma could be expected as absorption of the hematoma after previous bleeding. In the case of bleeding, radiosurgery in our patients was postponed for at least 3 months, but usually treatment was initiated 6 months after the bleeding episode. Therefore, a decrease in cavernoma volume after radiosurgery is a positive result of the treatment. The patients with decreased lesion volume were without rebleeding after GKRS. So the decrease in size of lesions should not be attributed to resorption of hemorrhage but radiation effect.

In our study, the risk of edema on follow-up MRI after radiosurgery was $13.6 \%$. Edema was associated with temporary morbidity in $13.6 \%$ of patients. There was no permanent morbidity in patients. One of them developed bleeding post gamma knife associated with edema.
In a study of 112 patients by lisck et al $2013^{5}$, the risk of edema on follow-up MRI after radiosurgery was $27.3 \%$. Edema was associated with temporary morbidity $14.6 \%$ of those with cavernomas. There was permanent morbidity in $0.9 \%$ of cavernoma patients. Statistical analysis in their study revealed that Edema after Gamma Knife treatment occurred more frequently in patients who had undergone prior surgery, those with a large cavernoma volume, and those in whom the dose to the cavernoma margin was $>13$ Gy .

In a group of 125 patients with cavernoma and a mean marginal dose of 12.1 Gy, Liu et al. 2005 ${ }^{6}$, observed symptom-matic complications in only 3 cases (their marginal doses was 14-15 Gy). They found that the only factor associated with a risk of AREs was the maximum dose.

Although Pollock et al. $2000{ }^{7}$ reported a reduction in the bleeding rate after radiosurgery in their series of 17 patients (reduced from $40 \%$ before radiosurgery to $2.9 \% 2$ years later), they found a radiationrelated morbidity rate of $41 \%$. This may have been due to the high median margin dose of $18 \mathrm{~Gy}$, leading to higher doses in the adjacent hemosiderin-stained brain.

Kim et al. $2014^{8}$ compared the incidence of two groups with different mean marginal doses of 14.6 and $18.3 \mathrm{~Gy}$, and discovered that the group with latter dose experienced a higher risk of encephaledema after GKR.

P.Wang et al. $2010^{9}$ compared incidence of edema among three different marginal dose groups $<15,15-17,>17$ gy and find the incidence of edema in the low marginal dose group was the lowest and conclude that low marginal dose can lower the incidence of edema.

Compared with surgical resection, the obvious disadvantage of radiosurgery is the latency interval necessary to achieve a reduction in the bleeding rate. This disadvantage is outweighed by the lower risk 
of radiosurgery for lesions completely located within critical brain parenchyma as brain stem.

Up to now, the only proof of treatment failure after radiosurgery is rebleeding or an increase in the cavernoma after the 2-year latent interval following radiosurgery.

\section{Conclusion:}

As the development of stereotaxic radiosurgery and more experience accumulated, GKR has become an effective and safe alternative method for CMs treatment, especially for those whose lesions are located where risk of surgical morbidity is deemed unacceptable and those who do not want to or cannot accept operation patients with multiple cavernomatosis.

It is safe enough to recommend GKR instead of having a wait-and watch policy for a neurologically intact patient.

\section{REFERENCES:}

1. Brehar F, Catana M, Pruna V, Gheorghiu A, Popescu G et al.: Surgical management of symptomatic spinal cord and intracerebral cavernomas in a multiple cavernomas case. Romanian Neurosurgery, 2016, 28-34.

2. YILMAZ, Tevfik, Cikla U, Başkaya M; CIKLA, Ulas; BAȘKAYA, Mustafa K. Microsurgical treatment of thalamic cavernous malformation: 3 Dimensional operative video. Operative Neurosurgery, 2015, 11.4: 577-577.

3. STEINER, Ladislau, Karlsson B, Yen CP,et al; Radiosurgery in cavernous malformations: anatomy of a controversy. Journal of neurosurgery, 2010, 113.1: 16-22.

4. AL-SHAHI SALMAN, Rustam, Berg MJ, Morrison L, Awad IA: Hemorrhage from cavernous malformations of the brain: definition and reporting standards. Stroke, 2008, 39.12: 3222-3230.

5. Liscak R., D. Urgosik, G. Simonova, et al; "Gamma knife radiosurgery of brain cavernomas." Gamma Knife Neurosurgery in the Management of Intracranial
Disorders. Springer, Vienna, 2013. 107111.

6. Liu KD, Chung WY, Wu HM, et al: Gamma knife surgery for cavernous hemangiomas: an analysis of 125 patients. Journal of neurosurgery, 2005, 102. Special Supplement: 81-86.

7. Pollock BE, Garces YI, Stafford SL,et al: Stereotactic radiosurgery of cavernous malformations. Journal of neurosurgery, 2000, 93.6: 987-991.

8. Kim Byung, Je Young Yeon, Jong-Soo Kim, Seung-Chyul Hong, Jung-Il Lee ; Gamma knife radiosurgery of the symptomatic brain stem cavernous angioma with low marginal dose. Clinical neurology and neurosurgery, 2014, 126: 110-114.

9. WANG, Peng, Zhang Fangcheng, Zhang Hongyun, Zhao Wuhan: Gamma knife radiosurgery for intracranial cavernous malformations. Clinical neurology and neurosurgery, 2010, 112.6: 474-477.

10. Giliberto, G., Lanzino, D. J., Diehn, F. E., Factor, D., Flemming, K. D., \& Lanzino, G.: Brainstem cavernous malformations: anatomical, clinical, and surgical considerations. Neurosurgical focus, 2010. 29(3), E9.

11. Gross, B. A., Batjer, H. H., Awad, I. A., Bendok, B. R., \& Du, R.: Brainstem cavernous malformations: 1390 surgical cases from the literature. World neurosurgery, 2013. 80(1-2), 89-93.

12. Amin-Hanjani S, Ogilvy CS, Candia GJ, et al. Stereotactic radiosurgery for cavernous malformations: Kjellberg's experience with proton beam therapy in 98 cases at the Harvard Cyclotron. Neurosurgery; 1998.42:1229-36.

13. Tsien C, Souhami L, Sadikot A, et al: Stereotactic radiosurgery in the management of angiographically occult vascular malformations. Int J Radiat Oncol Biol Phys ,2001. 50:133-138.

14. Hasegawa T, McInerney J, Kondziolka D,et al.: Long-term results after stereotactic radiosurgery for patients with cavernous malformations. Neurosurgery, 2002. 50:1190-1197

15. Kim DG, Choe WJ, Paek SH,et al: Radiosurgery of intracranial cavernous 


\section{Ahmed Ragab AbdelSalam, et al.,}

malformations. Acta Neurochir (Wien), 2002. 144:869-878

16. Kida Y, Kobayashi T, Mori Y: Radiosurgery of angiographically occult vascular mal-formations. Neurosurg Clin $\mathrm{N}$ Am, 1999 10:291-303.

17. Mitchell P, Hodgson TJ, Seaman S et al; Stereotactic radiosurgery and the risk of haemorrhage from cavernous malformations. Brit J Neurosurg, 2000 14:96-100.

18. Kondziolkaa D,b,d, John C. Flickingera,b, et al: Radiosurgery and Pathological Fundamentals. Radiosurgery for Cavernous Malformations Prog Neurol Surg. Basel, Karger, 2007. , vol 20, pp 220-230

19. Nagy G, Razak A, Rowe JG, et al; Stereotactic radiosurgery for deepseated cavernous malformations: a move toward more active, early intervention. J Neurosurg, 2013. 113:691-699

20. Monaco EA III, Khan AA, Niranjan A, et al. Stereotactic radiosurgery for the treatment of symptomatic brainstem cavernous malformations. Neurosurg Focus, 2010. 29:E11

21. Lunsford, L. D., Khan, A. A Niranjan A, Kano $\mathrm{H}$ et al Stereotactic radiosurgery for symptomatic solitary cerebral cavernous malformations considered high risk for resection. J Neurosurg, 2010. 113:23-29

22. Lee CC, David Hung-Chi Pan, Wen-Yuh Chung, et al; Brainstem cavernous malformations: the role of Gamma Knife surgery Clinical article J Neurosurg (Suppl), 2012. 117:164-169

23. Park SH, Hwang SK.; Gamma knife radiosurgery for symptomatic brainstem intra-axial cavernous malformations. World Neurosurg, 2012.

24. Sadeghi S;Parisa Azimi; Shahid Beheshti Sci;et al Cavernomas: Outcomes after Gamma-Knife Radiosurgery In Iran Journal of Research in Medical Sciences, 2014.

25. Zhang S., Lin S., Hui X., Li H., and You C.: Surgical treatment of cavernous malformations involving medulla oblongata. J Clin Neurosci2017. 37: pp. 63-68. 


\section{دور سكينة جاما فى علاج التثوهات الكهفية بجذع المخ.}

أحمد رجب، أيمن الثاذلي، أحمد فيصل، أحمد السبع، سامح رشدي

قسم جراحة المخ و الأعصاب, كلية الطب, جامعه عين شمس.

المقدم: الاورام الكهفية الدموية هى افات خفية لا تظهر عند تصوير الأوعية الدموية وهى تعرف بأنها جيوب و وعائية

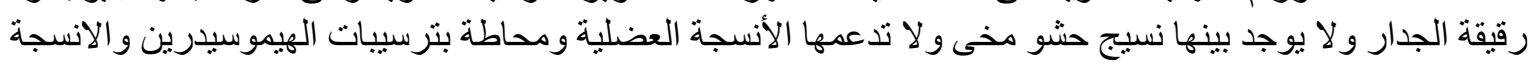

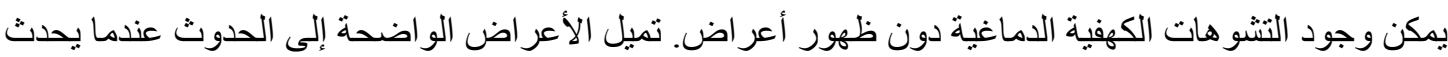

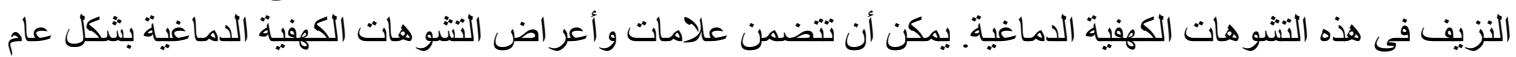

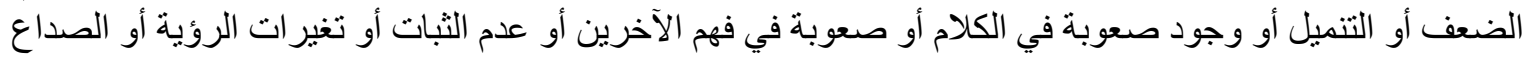

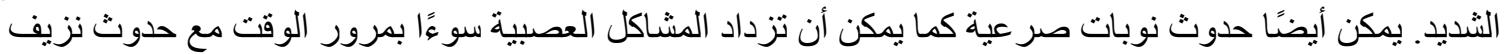

متكرر.

ويمكن ان تتو اجد هذه التشوهات باى مكان بالمخ و غالبا تكون فوق الخيمة بنسبة ثمانون بالمائة وتحت الخيمة بنسة

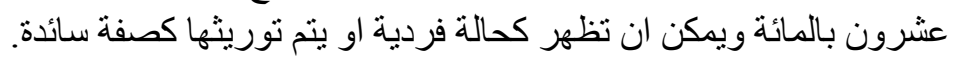

و هذه الافات ينتج عنها نزيف غالباو فى احيانا كثيرة يكون عديم الأعر اض و المعدل السنوي لحدوث هذا النزيف

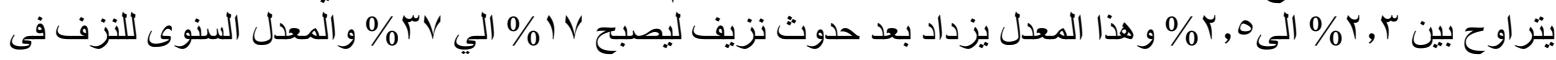

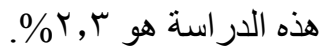

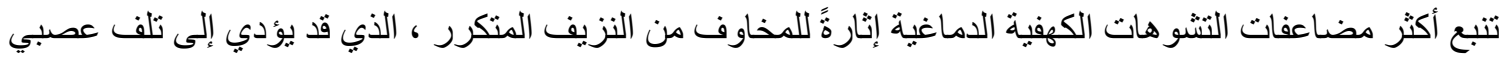

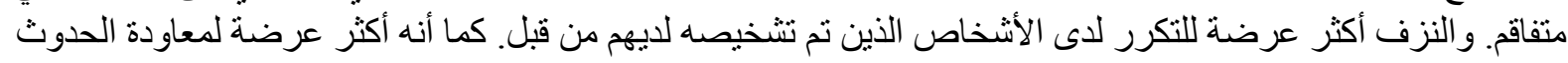
عند وجود نتو هات في جذع المخ.

ويعتبر الرنين المغناطيسي هو الوسيلة التشخيصية الأهم لهذه التشو هات. أما علاج هذه التشو هات يتضمن ثلات التهات طرق: العلاج التحفظى و العلاج الجر احى و الجر احة الاشعاعية عن طريق سكينة جاما .

الهدف: فيما يهدف هذا البحث في تقييم دور سكينة جاما فى علاج التشوهات الكهفية بجذع المخ و بيات مدى كفاءتها و درجة أمانها.

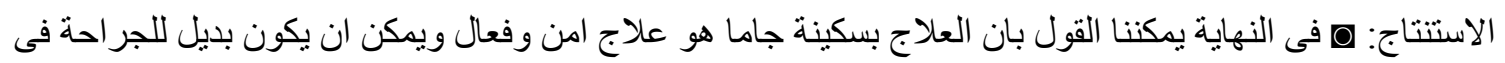

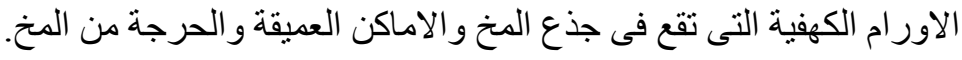

